\title{
EDUCATORS COMPETENCES FACING CHALLENGES OF DIGITAL TRANSFORMATION: A BRAZILIAN EXPERIENCE
}

Cristine Martins Gomes de Gusmão, Federal University of Pernambuco, Carlos Alberto Pereira de Oliveira, State University of Rio de Janeiro, Brazil

\section{Abstract}

Since March 11, the world has faced a major transformation in daily life, especially in the functions of professionals, with the announcement of the Covid-19 pandemic. New practices were implemented, and, in the educational area, educators began to deal directly with the evident need for technical and emotional skills in professional practice. The United Nations Development Program indicates, including through a framework, the importance of applying skills in professional practice. Education is no different, the program established those that should be the four pillars of education for the $21^{\text {st }}$ century: learn to know, learn to do, learn to live and learn to be. Within this context, this article presents actions taken for in-service training of public-school teachers in the State of Rio de Janeiro.

Keywords: Digital Competences; Digital Transformation; Public Basic Education

\section{Introduction}

In the last six months, due to the Covid-19 pandemic, as part of the challenge promoted by the educational disruption to which we were exposed, comes the need to deeply address remote learning and open and distance learning (ODL). In Brazil, the use of digital spaces to guarantee teaching and learning opportunities for all is still a problem, as professionals are not sufficiently trained in the application of technological mediation in education, in addition to the physical and technological infrastructure difficulties faced by public education. In this scenario, the Open Educational Movement and Practices, based in stimulate technical and emotional competences, are here to stay as a way for maintaining, at least in part, the functioning of the schools and universities.

Providing lifelong learning for all is an objective of UN-Agenda 2030. Vocational training is an ongoing effort to evolve, which allows for inclusive, equitable and quality education through educational actions around the world. It is important to highlight that the greatest 
professional gains lie in the particularity of all this experience to have occurred in a developing country like Brazil, a country that, due to its unique characteristics - having certain aspects of economic development as intense as the richest countries and, at the same time, regions where the human development index reaches very low levels, guarantee a wide world-like view of the diverse realities.

In the beginning of April, a Committee of Specialists from 7 Brazilian Public Higher Education Institutions (UFPE, UERJ, UFMT, IFES, Unifesp, UnB, UFRN), 1 Non-profit private HE institution (FGV), 1 international ODL organization (ICDE) and two Brazilian ODL Associations (ABED, Unirede) was formed with the objective of supporting the State Department of Education of the State of Rio de Janeiro, together with teams from the State Public Education Network, in the actions of maintaining remote learning, according to UNESCO - \#LearningNeverStops. The main need was to fill and close the gaps in the professional training of educators without experience in the use of Digital Information and Communication Technologies. Among the initial planned actions was in-service training as a way to support the entire network with 40,000 educators from elementary to high school and vocational programs involved, not counting all the administrative and pedagogical staff involved. In Rio de Janeiro, a group of specialists is organized in order to provide students in the State Public Education network with remote learning, through technological mediation, without neglecting the importance of the teacher-student relationship.

The "Education in Debate" Project (Projeto Educação em Debate - Open Sessions, 2020) brought a range of topics that covered contents focused on the practice of Open Distance Learning exposed by remote learning which was the most important option to face educational disruption caused by the pandemic. The role of technological mediation was addressed in its punctuality, especially considering the vulnerable and low-income populations of which a large number of students and families are part. For the selection of topics and speakers, the Committee took into account the European Framework for the Digital Competence of Educators: DigCompEdu (Redecker \& Punie, 2017).

To better understand the development of the project, after this introductory section in the following sections, we present the methodological approach, discuss the main results and present final considerations.

\section{Materials and Methods}

The initial project planning was provided for 8 open sessions. With the development of the project, the outcomes presented were encouraging and the group of participating teachers demanded new sessions grouped in two new rounds, totalling 17 sessions. The average number of attendees per session was 1,200. 


\section{Competencies}

Based on the European Framework for the Digital Competence of Educators: DigCompEdu (Redecker \& Punie, 2017) and core competencies from The Competency Framework - United Nations Development Programme (UNDP, 2008) we define three cycles of presentations, as shown in Table 1.

Table 1: Cycles and Target Competences

\begin{tabular}{ll}
\hline Cycle & Target Competence \\
\hline Sessions 1, 2, 3,4 & Ethics and Values \\
& Appropriate and Transparent decision making \\
& Organizational Awareness \\
Sessions 5, 6, 7, 8,9 & Communicating Information and Ideas \\
& Self-management and Emotional Intelligence \\
& Conflict management | Negotiating and Resolving \\
& Disagreements \\
Sessions 10,11,12,13,14,15,16,17 & Developing and Empowering People | Coaching and \\
& Mentoring \\
& Knowledge sharing | Continuous learning \\
& Working in teams \\
\hline
\end{tabular}

The model presents a grade of a proficiency levels. Most of our attendees were placed as a Newcomer, level A1. As mentioned, (Redecker \& Punie, 2017; p.30)

"Newcomers are aware of the potential of digital technologies for enhancing pedagogical and professional practice. However, they have had very little contact with digital technologies and use them mainly for lesson preparation, administration or organisational communication. Newcomers need guidance and encouragement to expand their repertoire and to apply their existing digital competence in the pedagogical realm."

And a minor group was considered as Explorer, level A2.

"Explorers are aware of the potential of digital technologies and are interested in exploring them to enhance pedagogical and professional practice. They have started using digital technologies in some areas of digital competence, without, however, following a comprehensive or consistent approach. Explorers need encouragement, insight and inspiration, e.g. through the example and guidance of colleagues, embedded in a collaborative exchange of practices." 


\section{Sessions}

According to this type of proficiency level, we started to schedule the sessions. The sessions were defined in panel format, involving 2 to 4 speakers and a mediator. Mediation was carried out by a specialist from the Committee of Specialists. All the video material was recorded and are open educational resource, licenced with CC Attribution - ShareAlike 4.0 International.

\section{Results and Discussion}

Working on real-world problems usually requires the combination of different kinds of specialized and context-dependent knowledge, as well as different ways of knowing (Markauskaite \& Goodyear, 2018). Defining the panels sessions, we were anxious to achieve this balance. It is important to highlight that all sessions were linked to the sustainable development goals 2, 3, 4, 5, 6, 8, 9, 10, 16 and 17 (United Nations, 2015).

In the first cycle of sessions, we emphasize skills related to ethics and professional values, the importance of having the right data ensuring appropriate and transparent decisionmaking and an organizational awareness as a way to promote the commitment of management and employees. Four sessions were realized, and the main themes were:

- Public Education, Pandemic and International Cooperation: \#LearningNeverStops - In this first session we brought the importance of lifelong learning looking at Sustainable Development Goals - Agenda 2030.

- The new teacher: challenges of education in times of pandemic - The main point discussed in this session was the importance of technological mediation in remote education. Teacher training was discussed with a focus on non-classroom teaching activities, innovation in professional practice and new skills in the digital age.

- Technology, digital inclusion and social inclusion: are we ready? - This session was characterized by the presentation of research, carried out in 2018 (Cetic.br, 2018) and studies on the use of Information and Communication Technologies in Brazilian schools. The discussion was directed to the reality of the population and vulnerabilities related to remote activities in public schools. The majority of the population is poor and lacks food, support and security, mainly domestic.

- The legacy to post-pandemic education: technological mediation, open educational resources and more open and flexible education - Once in distance learning, topics related to student and teacher learning guided the discussion. Questions such as developing material for the remote classroom, working on motivation and encouraging participation, dealing with remote schedules, contrary to what is done in face-to-face education, were answered by addressing topics such as Open 
Educational Resources, Open and Flexible Learning reinforcing the importance licensing and copyright.

In the second cycle of the sessions, the work focused mainly on supporting the development of activities, considering the return of classes in remote format for vulnerable populations. The main themes were:

- Evaluation from the perspective of new educational methodologies - This debate specifically addressed student assessment issues in remote learning. Brazilian legislation was the focus.

- Health and Education: Essential Binomial - The return to face-to-face classes is strongly related to issues of assistance and public health. With the Covid-19 cases and the possibility of a return, in the new normal, representatives of the state government of Rio de Janeiro brought their contributions and made their considerations.

- New ways of thinking about goals and Contents in Education - The physical distance brought up important social issues. This session discussed creative alternatives in the teacher-student relationship in virtual environments. Technical and emotional skills were evidenced.

- The inclusion of vulnerable populations in the new educational process - Work in the Brazilian and Portuguese prison system, in times of pandemic, was carried out in this session.

- The return to school life after pandemic - Practices and solutions from Portugal were presented, in view of the ongoing actions in Brazil to return to face-to-face activities in schools and universities.

The last cycle brought discussion and concern with actions to resume face-to-face activities. The organizational vision is extremely important, and the commitment established with the community of parents, employees and public authorities, brings the educational institution as a link. The debates were:

- Competences and remote learning: a look at the Common National Curricular Base - This session explored the competencies defined for early childhood, secondary, elementary and professional education, by the Ministry of Education.

- Teaching and learning from the perspective of technological mediation - Network partnerships and cooperation were presented and encouraged as alternatives to balance institutional demands.

- School and educational planning in the current context - Educational institutions are concerned with defining their hybrid education plans, as well as return protocols according to the health and public health situation in each state. This session discussed important points for knowledge sharing and continuous learning. 
- School and learning assessment in the current context - How to deal with learning issues and effective understanding of the contents taught? The basis for discussion is reasonableness and protocols established.

- School and the challenge of permanence - In this session the focus was the largest disruption of education systems and impacts from closures schools in low and lower-middle income countries (United Nations, 2020).

- School and innovative practices in today's context - Second Open Session dealing with Innovation as a pillar of blended learning particularly during and after the pandemic

- Innovative Practices in Blended Learning - Innovation is a pillar of blended learning particularly during and after the pandemic.

- Can we resume face-to-face activities in schools? What Science says - In this last Open Session, with the participation of the former highly recognized former Brazilian Minister of Health and the Chief of Cabinet of the Extraordinary COVID19 Secretariat, just in the planned return weeks, openly show scientific data to show that we are ready to go blended.

All debates had a good participation and interaction by the state public teachers and other professionals who attended the sessions. The speakers played a fundamental role, bringing important experiences in the most diverse areas of domain.

\section{Final Considerations}

We still have a lot to do. We reflected on the post-COVID-19 and the adequacy to UNESCO recommendations. We have the challenges of thinking about how schools will reopen and the protocols to face the pandemic in the school setting; the gradual return to face-to-face activities; how to support staff and students in regard to mental health, which may have been affected by physical distance and the various losses that students and staff faced during this year; implement actions that guarantee the return to school of all students so as to avoid school dropout; develop actions that guarantee the resumption of studies; and, always attentive to the principle of equity, provide adequate learning opportunities for all, identifying the needs of each student; and validating the learning process and the workload of the activities developed during physical distance.

Above all, we are absolutely committed to the "Futures of Education" when "learning never stops" and no one will be left behind. 


\section{References}

Markauskaite, L., \& Goodyear, P. (2018). Universities should take stronger leadership on knowledge and how it matters. University of Sidney. Retrieved from https://theconversation.com/universities-should-take-stronger-leadershiponknowledge-and-how-it-matters-89849

Open Sessions (2020). Retrieved from https://sites.google.com/educa.rj.gov.br/aprendizagemnuncapara/

Redecker, C., \& Punie, Y. (2017). European Framework for the Digital Competence of Educators: DigCompEdu. Retrieved from https://ec.europa.eu/jrc/en/publication/eurscientific-and-technical-research-reports/european-frameworkdigital-competenceeducators-digcompedu

Cetic.br (2018). Pesquisa sobre o uso das Tecnologias de Informação e Comunicação nas escolas brasileiras - TIC Educação. Retrieved from https://cetic.br/pt/publicacao/pesquisa-sobre-o-uso-das-tecnologias-de-informacao-ecomunicacao-nas-escolas-brasileiras-tic-educacao-2018/

United Nations (2015). Agenda 2030. Retrieved from https://nacoesunidas.org/pos2015/agenda2030/

United Nations (2020). Policy Brief: Education during COVID-19 and beyond. Retrieved from https://www.un.org/development/desa/dspd/wpcontent/uploads/sites/22/2020/08/sg_policy_brief_covid19_and_education_august_2 020.pdf

UNDP - United Nations Development Programme. (2008). Competency Framework. Retrieved from https://procurement-notices.undp.org/view_file.cfm?doc_id=10206

\section{Acknowledgements}

The project thanks the participation of all employees of the State Secretariat of Education of Rio de Janeiro, the Committee of Specialists, the Brazilian and Portuguese experts, who kindly accepted the invitation to discuss the directions of Education in times of pandemic, and all the institutions of higher education that supported this project. We dedicate the project to all professionals who advocate for access and good education for all and who are always committed to the desire for knowledge, and to all students who will be responsible for keeping this flame burning in the new normal in this digital society. 